\title{
0435. Pressure-support ventilation compared to pressure-controlled ventilation in experimental emphysema
}

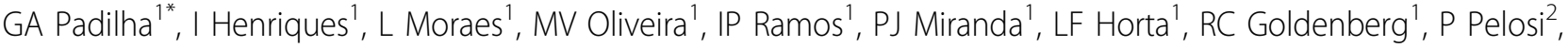 \\ PL Silva ${ }^{1}$, PRM Rocco ${ }^{1}$
}

From ESICM LIVES 2014

Barcelona, Spain. 27 September - 1 October 2014

\section{Introduction}

Emphysema is characterized by irreversible enlargement of the airspaces distal to the terminal bronchiole, accompanied by destruction of their walls, and impairment of cardiac function. Acute exacerbation of emphysema leads to increased morbidity, mortality and, in some cases, requirement of invasive mechanical ventilation (MV). So far, no study has compared the impact of pressure-controlled ventilation (PCV) and pressure-support ventilation (PSV) on lung mechanics and histology as well as cardiac function in experimental emphysema.

\section{Objectives}

Our aims were

1) to develop an elastase-induced emphysema model in rats that results in lung mechanical and histological impairment and cor pulmonale; and

2) to compare the effects of PCV and PSV on lung and heart.

\section{Methods}

Thirty-six Wistar rats were randomly divided into 2 groups. In ELA group, rats received porcine pancreatic elastase (2 IU) intratracheally, once a week, during 4 weeks, whereas SAL group was treated with saline. Lung mechanics and histology, as well as echocardiography were analyzed at $4,6,8$, and 11 weeks. Additional thirty-two animals were treated with saline $(n=16)$ and elastase $(n=16)$ using the same protocol previously described and randomized according to ventilator strategy: pressure-controlled ventilation (SAL-PCV and ELA-

${ }^{1}$ Federal University of Rio de Janeiro, Carlos Chagas Filho Biophysics Institute, Rio deJaneiro, Brazil

Full list of author information is available at the end of the article
$\mathrm{PCV}, \mathrm{n}=8 / \mathrm{each}$ ) and pressure-support ventilation (SALPSV and ELA-PSV, $n=8 /$ each). Tidal volume was kept constant (» 6-8 $\mathrm{ml} / \mathrm{kg}$ ) Lung mechanics and echocardiography were performed at the beginning (Initial) and 4 hours MV (Final), after which lungs were removed for morphometric analysis.

\section{Results}

Compared to SAL group, ELA animals showed increased specific elastance, functional residual capacity, mean alveolar diameter, and right ventricle area at $6(61 \%, 37 \%$, $64 \%$, and $8 \%$, respectively) and 8 weeks $(37 \%, 37 \%, 40 \%$, and $16 \%$, respectively). At 11 weeks, no significant changes were observed in lung mechanics but Lm (53\%) and right ventricle area (20\%) remained elevated. Based on these data we opted to compare the mechanical ventilation strategies at 8 weeks. Mean airway pressure $\left(\right.$ Pmean, $\left.{ }_{\mathrm{aw}}\right)$ was lower in ELA-PSV compared to ELAPCV at the Final $(p<0.01)$. Transpulmonary peak pressure (Ppeak,L) was more reduced in ELA-PSV in Final compared to Initial $(\mathrm{p}<0.05)$. PCV resulted in greater areas of alveolar hyperinflation compared to PSV ( $<<$ 0.05 ). The ratio between the pulmonary artery acceleration time and the pulmonary artery ejection time (PAT/ PET) increased in ELA-PSV (16\%) along time, but not in ELA-PCV, suggesting reduction in pulmonary arterial hypertension.

\section{Conclusion}

In the current elastase-induced emphysema, we found that: 1) 8 weeks was the time associated to lung mechanical and histological changes and cardiac impairment that resemble human emphysema; and 2) PSV 
attenuated lung mechanics, hyperinflation, and cardiovascular dysfunction compared to PCV.

\section{Supported by}

\section{CNPq, FAPERJ, CAPES, PRONEX, INCT-INOFAR}

\section{Authors' details}

'Federal University of Rio de Janeiro, Carlos Chagas Filho Biophysics Institute, Rio deJaneiro, Brazil. ${ }^{2}$ University of Genoa, Department of Surgical Sciences and Integrated Diagnostics, Genoa, Italy.

Published: 26 September 2014

doi:10.1186/2197-425X-2-S1-P27

Cite this article as: Padilha et al:: 0435 . Pressure-support ventilation compared to pressure-controlled ventilation in experimental emphysema. Intensive Care Medicine Experimental 2014 2(Suppl 1):P27.

\section{Submit your manuscript to a SpringerOpen ${ }^{\mathcal{D}}$ journal and benefit from:}

- Convenient online submission

- Rigorous peer review

- Immediate publication on acceptance

- Open access: articles freely available online

- High visibility within the field

- Retaining the copyright to your article 